\title{
Results and Long-Term Functional Outcomes of Rib Fracture Fixation: A Case Series in Singapore and a Review of Indications for Surgical Fixation
}

\section{Dear Editor,}

Chest injuries are common-rib fractures are present in approximately $21 \%$ of patients with blunt chest trauma. ${ }^{1}$

Rib fractures are associated with significant morbidity. Patients require admission to the intensive care unit (ICU) and mortality rates are reported to be as high as $33 \%{ }^{2,3}$ Acute problems associated with rib fractures include prolonged mechanical ventilation and length of stay (LOS), higher incidence of tracheostomy, pneumonia and mortality. ${ }^{4}$ Postinjury, the mean number of days lost from work or usual activity per patient was $70 \pm 41$ days. ${ }^{5}$ In the long-term, rib fractures are associated with chronic problems such as pain, chest wall deformity, reduced quality of life (QOL), functional loss and socioeconomic costs. ${ }^{4}$

Increasingly, studies have shown that there might be a role for surgical fixation of rib fractures. Surgical stabilisation of ribs leads to earlier weaning from ventilator support, reduces acute complications and prevents chronic pain, which may be associated with permanent chest wall deformities. ${ }^{6}$ Despite the reported clinical benefits, rib fracture fixation remains an underutilised procedure in Singapore. The aim of this study was to describe the results and long-term functional outcomes of our experience with rib fracture fixation.

\section{Materials and Methods}

A retrospective review of all patients with rib fractures between 2012-2016 was performed. Data was collected from electronic medical records and a telephone survey was performed to assess long-term functional outcomes. The results obtained from this study were compared with 2 studies with similar indications for surgery (that looked at long-term outcomes of rib fracture fixation and a control group of rib fractures that were treated conservatively). A literature review of the indications for surgical fixation of rib fractures was also discussed.

Flail chest—involving fracture of $\geq 3$ ribs at $\geq 2$ sites $^{7}$ was diagnosed radiographically. Precontoured titanium rib locking $1.5 \mathrm{~mm}$ plates (MatrixRIB ${ }^{\mathrm{TM}}$, DePuy Synthes) were used. When necessary, video thoracoscopy was performed for pleural toilet and clot removal.

\section{Results}

In the study period, 21 patients with a mean age of 66.5 (range, 19-77) years old underwent rib fracture fixation (Table 1).

\section{Mechanism of Injury}

Approximately half of the injuries $(61.9 \%, \mathrm{n}=13)$ were due to road traffic crashes and $38 \%(n=8)$ of patients had fallen from a height.

\section{Chest Injury}

The median injury severity score was 16 (range, 9-32) out of 75 . The median chest injury score was 4 (range, 3-5) out of 6 . Fourteen percent $(n=3)$ of patients had bilateral rib fractures; $91 \%(n=19)$ of injuries were associated with pneumothorax and $71 \%(\mathrm{n}=15)$ had hemothorax. Preoperative chest tube insertion was required in $76 \%$ (n $=16$ ) of patients. There were concomitant scapular and/or clavicular fractures in $24 \%(\mathrm{n}=5)$ of patients. The mean number of ribs injured per person was 5.8. Depending on the fracture location, the majority of cases were fixed using the posterolateral approach (Table 1).

\section{Location of Rib Fractures}

The $4^{\text {th }}-8^{\text {th }}$ ribs were the levels that were most often fractured and fixed. Ribs 1 and 2 were not fixed due to access issues and ribs 10-12 were not routinely fixed, as they were not critical to respiratory mechanics. Posterior defects under the scapula were not routinely fixed as well (the anterior chest wall is more mobile and has a more significant impact on respiratory mechanics). Mansour et $\mathrm{al}^{8}$ found that skeletal reconstruction is not necessary for defects under the scapula or above the $4^{\text {th }}$ rib.

\section{Time to Surgery}

Patients often had multiple injuries and required preoperative optimisation. Twenty-nine percent $(n=6)$ of patients sustained associated fractures of the extremities, $9.5 \%(\mathrm{n}=2)$ each had facial fractures and intra-abdominal injuries and $5 \%(\mathrm{n}=1)$ had intracranial injuries. The mean time from injury to surgery was 4.7 (range, $0-19$ ) days. 
Table 1. Patient Demographics and Injury Profile $(n=21)$

\begin{tabular}{|c|c|}
\hline Variable & n (\%) \\
\hline \multicolumn{2}{|l|}{ Gender } \\
\hline Male & $16(76)$ \\
\hline Female & $5(24)$ \\
\hline Comorbidities, ${ }^{*}$ median (range) & $2(1-3)$ \\
\hline \multicolumn{2}{|l|}{ Mechanism of injury } \\
\hline Road traffic accident & $13(62)$ \\
\hline Fall from height & $8(38)$ \\
\hline \multicolumn{2}{|l|}{ Rib fractures } \\
\hline Unilateral & $18(86)$ \\
\hline Bilateral & $3(14)$ \\
\hline \multicolumn{2}{|l|}{ Location of rib fracture(s) } \\
\hline Anterior & $6(29)$ \\
\hline Posterior & $10(48)$ \\
\hline Lateral & $19(90)$ \\
\hline \multicolumn{2}{|l|}{ Operative approach(es) } \\
\hline Anterior & $4(19)$ \\
\hline Posterior & $13(62)$ \\
\hline Lateral & $18(86)$ \\
\hline Sternal midline & $3(14)$ \\
\hline \multicolumn{2}{|l|}{ Pneumothorax } \\
\hline Unilateral & $16(76)$ \\
\hline Bilateral & $3(14)$ \\
\hline \multicolumn{2}{|l|}{ Hemothorax } \\
\hline Unilateral & $15(71)$ \\
\hline Bilateral & $0(0)$ \\
\hline Preoperative chest tube & $16(76)$ \\
\hline \multicolumn{2}{|l|}{ Injury scores, mean $\pm \mathrm{SD}$} \\
\hline Injury Severity Score ${ }^{\dagger}$ & $17.7(9 \pm 32)$ \\
\hline Chest Injury Score & $3.7(3 \pm 5)$ \\
\hline \multicolumn{2}{|l|}{ Other injuries ${ }^{\ddagger}$} \\
\hline Intracranial & $1(5)$ \\
\hline Facial & $2(9.5)$ \\
\hline Intra-abdominal & $2(9.5)$ \\
\hline Extremity & $4(19)$ \\
\hline
\end{tabular}

SD: Standard deviation

*According to the American Society of Anesthesiologists classification. Out of 75 .

Out of 6 .

\section{Indication(s) for Surgery}

The indications for surgery were multifactorial (Table 2). Most patients had $>1$ indication for surgery. Nearly half of patients $(48 \%, \mathrm{n}=10)$ had flail chest. Other indications include significantly displaced fractures $(38 \%, \mathrm{n}=8)$, intractable pain not controlled by conventional measures $(29 \%, \mathrm{n}=6)$, inability to wean off the ventilator $(5 \%, \mathrm{n}=1)$, bleeding
$(24 \%, n=5)$, decortication for empyema $(24 \%, n=5)$ and persistent air leak $(10 \%, \mathrm{n}=2)$. The majority of patients $(62 \%, n=13)$ had concomitant thoracotomy-rib fracture fixation was performed at the end of this surgery.

\section{Intensive Care Unit}

Nine $(43 \%)$ patients were admitted to the ICU postoperatively with a mean ICU stay of 1.3 days. Five (24\%) patients were kept intubated postoperatively as a prophylactic measure (especially in cases of decortication) to provide positive pressure for lung expansion. All of them were extubated the next day. The mean overall intubation duration and mean overall ICU stay of all patients who underwent rib fracture fixation is 0.2 (range, $0-1$ ) days and 0.6 (range, $0-2$ ) days, respectively.

\section{Pain Control}

All patients received postoperative pain optimisation from the Acute Pain Service (APS). Intercostal nerve block was the most common postoperative analgesia $(62 \%, n=13)$. Thirty-eight percent $(n=8)$ received patient-controlled analgesia while $14 \%(n=3)$ had epidural. The mean duration of APS was 4.3 (range, 3-6) days.

\section{Hospitalisation}

The median overall hospitalisation duration was 10 (range, 3-29) days. The median overall postoperative hospitalisation duration was 6 (range, 3-13) days.

\section{Complications}

There were no cases of wound infection, reoperation or perioperative mortality. One patient $(4.8 \%)$ had a fixation screw that became partially detached from the plate (the patient was asymptomatic and was treated conservatively). Two (9.5\%) patients complained of chest numbness, and $1(4.8 \%)$ had areas of hypertrophic scarring. No patient underwent removal of implants. No cases of non-union were identified.

\section{Long-Term Outcomes \\ Follow-up}

The mean follow-up period was 2.7 (range, 2.5-5.8) years. Out of 21 patients, $14(67 \%)$ were contactable via phone, $6(29 \%)$ were uncontactable, and $1(5 \%)$ patient had deceased.

\section{Long-Term Pain}

Thirty-six percent $(\mathrm{n}=5)$ of respondents had no long-term pain, $50 \%(n=7)$ had pain on exertion only and $14 \%(n=$ 2) experienced discomfort on deep breathing. None of the patients had pain at rest. The majority of the pain had resolved postoperatively within 1 week in $14 \%(n=2)$ of patients; 
Table 2. Comparison of Results With Other Studies

\begin{tabular}{|c|c|c|c|c|}
\hline Variable & Results $(n=21)$ & Majercik $^{*}(n=101)$ & Mayberry $^{\dagger}(n=46)$ & $\operatorname{Marasco}^{\ddagger}(n=397)$ \\
\hline Age (mean) & 66.5 & 57 & 46 & 53.9 \\
\hline \multicolumn{5}{|l|}{ Indications for surgery, n (\%) } \\
\hline Flail chest & $10(48)$ & $64(63)$ & $18(39)$ & \\
\hline Displaced fracture & $8(38)$ & $23(23)$ & $15(33)$ & \\
\hline Intractable pain & $6(29)$ & $37(37)$ & $15(33)$ & \\
\hline Thoracotomy for other reasons & $12(57)$ & & $3(7)$ & \\
\hline Chest deformity & & & $5(11)$ & \\
\hline Pulmonary herniation & & & $3(7)$ & \\
\hline Injury Severity Score (mean) & 17.7 & 22 & 30 & 22.5 \\
\hline Chest Injury Score (mean) & 3.7 & 3.4 & 4 & 3 \\
\hline \multicolumn{5}{|l|}{ Intensive care unit } \\
\hline Admission (\%) & 43 & 76 & & \\
\hline Postoperative intubation (\%) & 24 & & & \\
\hline Intubation time (days, median $\pm \mathrm{SD}$ ) & $0(0 \pm 1)$ & & & \\
\hline Intensive care unit LOS (days, median $\pm \mathrm{SD}$ ) & $0(0 \pm 2)$ & $1(0 \pm 3)$ & & \\
\hline Hospital LOS (days, median \pm SD) & $10(3 \pm 29)$ & $8(6 \pm 11)$ & & $8(4 \pm 13)$ \\
\hline \multicolumn{5}{|l|}{ Postoperative analgesia } \\
\hline Intercostal nerve block (\%) & 62 & & & \\
\hline Patient-controlled analgesia (\%) & 38 & & & \\
\hline Epidural (\%) & 14 & & & \\
\hline Duration of APS (days, mean) & 4.3 & & & \\
\hline Follow-up (months) & 47 & 16 & 48.5 & 24 \\
\hline Current pain $(\%)$ & 14 & 16 & & $20 \|$ \\
\hline Pain score,$\S($ median $\pm \mathrm{SD})$ & $1(0 \pm 5)$ & & & \\
\hline Pain at rest $(\%)$ & 0 & & & \\
\hline Pain on deep breath $(\%)$ & 14 & & & \\
\hline Pain on exertion $(\%)$ & 50 & & & \\
\hline No pain $(\%)$ & 33 & & & \\
\hline Chronic narcotics $(\%)$ & 0 & 4 & & \\
\hline McGill Pain Rating Index & & & $6.7^{\#}$ & \\
\hline \multicolumn{5}{|l|}{ Functional outcomes (\%) } \\
\hline Unable to do strenuous activities & 14 & & & \\
\hline No limitations & 86 & 92 & & 55 \\
\hline Return to baseline activities/work & 79 & 92 & & 59 \\
\hline Disabled & 0 & & 11 & 11 \\
\hline Short Form-12 Health Survey & & & & Worse \\
\hline RAND-36 Health Survey & & & No difference & \\
\hline Patient satisfaction," (median \pm SD) & $8(3 \pm 10)$ & 9.2 & & \\
\hline
\end{tabular}

APS: Acute Pain Service; LOS: Length of stay; SD: Standard deviation

"Majercik S, Cannon Q, Granger SR, VanBoerum DH, White TW. Long-term patient outcomes after surgical stabilization of rib fractures. Am J Surg 2014;208:88-92.

'Mayberry JC, Kroeker AD, Ham LB, Mullins RJ, Trunkey DD. Long-term morbidity, pain, and disability after repair of severe chest wall injuries. Am Surg 2009;75:389-94.

${ }^{\ddagger}$ Marasco S, Lee G, Summerhayes R, Fitzgerald M, Bailey M. Quality of life after major trauma with multiple rib fractures. Injury 2015;46:61-5.

${ }^{\S}$ Out of 10.

'More than 5 out of 10.

${ }^{\#}$ Out of 78 . 
1 month in $21 \%(\mathrm{n}=3)$ of patients; and 3 months in $36 \%$ $(n=5)$ of patients. Fourteen percent $(n=2)$ of patients experienced significant pain, which lasted for $>1$ year. Both patients suffered from diabetes mellitus, which may contribute to their neuropathic pain. None of the patients required regular analgesia for long-term pain control.

\section{Return to Baseline}

Seventy-nine percent $(\mathrm{n}=11)$ of patients had returned to their preoperative baseline function or job. The remaining $21 \%(\mathrm{n}=3)$ were unable to do strenuous exercises but were able to perform their activities of daily living.

\section{Patient Satisfaction}

Of the 14 respondents, 13 (93\%) were satisfied with the results of the operation (only 1 did not find any improvement after the operation). On a scale of $1-10$, the mean and median scores were 8 and 9 , respectively. All participants (except for 1 patient) scored their satisfaction with the operation 7 and above. The sole patient gave a score of 3 due to loosening of a screw, which he felt limited his initial rehabilitation.

\section{Discussion}

The indications for surgical fixation of rib fractures have been heavily debated in surgical literature without resolution.

\section{Flail Chest}

Flail chest is a relatively strong indication for surgery. A meta-analysis found that operative management was associated with reduction in duration of mechanical ventilation, ICU stay, hospitalisation, mortality, incidence of pneumonia and use of tracheostomy. ${ }^{9}$ In 2010, the United Kingdom's National Institute for Health and Clinical Excellence recommended stabilisation of flail chest based on consistent evidence of its efficacy and lack of major safety concerns. ${ }^{6}$

\section{Significantly Displaced Rib Fractures}

Rib fracture sites are prone to shear movement due to constant movement with respiration and this is associated with delayed diaphyseal healing (compared to axial movement which stimulates healing). A systematic review ${ }^{10}$ clearly supports surgical stabilisation of isolated multiple distracted ribs for improving painful outcomes, respiratory function and improved QOL with reduced socio-professional disability.

\section{Pain and Disability}

Acute pain from rib fractures prevents mobility and inhibits respiratory effort. Rib fractures treated non-surgically can lead to prolonged chest wall pain and prolonged disability in $59 \%$ and $76 \%$ of patients, respectively. ${ }^{11}$ Patients undergoing rib fixation have been shown to have significant reductions in morphine requirements. ${ }^{12}$

\section{Symptomatic Non-Union}

Non-union of rib fractures causes chest wall deformity, non-physiologic motion of the chest wall and chronic debilitating pain. Non-unions are uncommon; however, when they do occur, surgical treatment has proven to be successful in achieving bony union, pain relief and stability of the chest wall. ${ }^{13}$

Unlike the study by Mayberry et al, ${ }^{14}$ more liberal indications for rib fracture fixation were used in our study. Singapore patients are generally active and often anxious to get back to work or leisure activities. The authors have found that for patients with significantly displaced ribs, flail chest or pain that is not controlled, rib fracture fixation resolves their pain quickly and enabled patients to resume their previous activities.

\section{Long-Term Outcomes of Rib Fracture Fixation}

Evidence looking at the long-term benefits and QOL of patients who have undergone rib fracture fixation is scarce., ${ }^{4,15}$ Results from this study were compared with similar studies looking at long-term outcomes of rib fracture fixation (Table 2). Two studies-Majercik et a $\mathrm{l}^{15}$ and Mayberry et $\mathrm{al}^{14}$ - that had similar indications for surgical fixation were identified, as was a paper by Marasco et $\mathrm{a}^{16}$ that analysed long-term outcomes after conservative management (which served as a control group). Though this study's patient profile was significantly older, the chest's Injury Severity Score and time from injury to surgery were similar to the other studies. For acute outcomes, results showed similar hospital LOS and relatively lower postoperative ICU admission rate. The mean duration of significant postoperative pain was 5.9 weeks (compared to Mayberry et al's study ${ }^{14}$ time of 4.7 weeks). At an average follow-up of 47 months, 2 patients were still experiencing pain, but the mean pain score was 1.3 out of 10 , (compared to the conservative group ${ }^{16}$ where after 24 months, $20 \%$ of patients still experienced a pain score of at least 5 out of 10). For functional outcomes, $79 \%$ of patients could return to their baseline preinjury activities or work (in Majercik et al's study, ${ }^{15} 92 \%$ could return to work with a mean time of 7.9 weeks). In the conservative group, ${ }^{16}$ only $59 \%$ of patients could return to work at 24 months, and $11 \%$ were disabled. The varied assessment tools and duration of follow-up limit comparisons of these studies. Nonetheless, the trend of results in all 3 surgical groups were similar. This suggests that surgical fixation of rib fractures brings long-term clinical and possible socioeconomic benefits. 


\section{Conclusion}

The present study has demonstrated that patients who undergo rib fracture fixation are able to wean off narcotics in a reasonable amount of time, have short durations of mechanical ventilation and ICU stays, low rates of chest wall deformity and/or chronic pain, and are very satisfied with the procedure. Furthermore, the majority of patients were able to participate in baseline preinjury activities without significant limitations.

However, several limitations to the study have been identified. First, the retrospective nature of the study. Second, this series lacked suitable matched-control patients. Polytrauma patients are an inherently heterogeneous group with associated non-thoracic injuries, which serve as confounding factors influencing the perception of pain, function, activity and QOL. Other limitations include the small population size, variety of surgical techniques and indications used. This study serves as a roadmap and hopes to encourage further study in this important area.
8. Mansour KA, Thourani VH, Losken A, Reeves JG, et al. Chest wall resections and reconstruction: a 25-year experience. Ann Thorac Surg 2002;73:1720-5.

9. Leinicke JA, Elmore L, Freeman BD, Colditz GA. Operative management of rib fractures in the setting of flail chest: a systematic review and metaanalysis. Ann Surg 2013;258:914-21.

10. Girsowicz E, Falcoz PE, Santelmo N, Massard G. Does surgical stabilization improve outcomes in patients with isolated multiple distracted and painful non-flail rib fractures? Interact Cardiovasc Thorac Surg 2012;14:312-5.

11. Fabricant L, Ham B, Mullins R, Mayberry J. Prolonged pain and disability are common after rib fractures. Am J Surg 2013;205:511-5; discusssion 515-6.

12. de Moya M, Bramos T, Agarwal S, Fikry K, Janjua S, King DR, et al. Pain as an indication for rib fixation: a bi-institutional pilot study. J Trauma 2011;71:1750-4.

13. Cacchione RN, Richardson JD, Seligson D. Painful nonunion of multiple rib fractures managed by operative stabilization. J Trauma 2000;48:319-21.

14. Mayberry JC, KroekerAD, Ham LB, Mullins RJ, Trunkey DD. Long-term morbidity, pain, and disability after repair of severe chest wall injuries. Am Surg 2009; 75:389-94.

15. Majercik S, Cannon Q, Granger SR, VanBoerum DH, White TW. Longterm patient outcomes after surgical stabilization of rib fractures. Am J Surg 2014;208:88-92.

16. Marasco S, Lee G, Summerhayes R, Fitzgerald M, Bailey M. Quality of life after major trauma with multiple rib fractures. Injury 2015;46:61-5.

\section{REFERENCES}

1. Cameron P, Dziukas L, Hadj A, Clark P, Hooper S. Rib fractures in major trauma. Aust N Z J Surg 1996;66:530-4.

2. Pressley CM, Fry WR, Philp AS, Berry SD, Smith RS. Predicting outcome of patients with chest wall injury. Am J Surg 2012;204:910-3; discussion 913-4.

3. Kwa BH. Experiences in the management of chest injuries and a review of current management. Ann Acad Med Singapore 1983;12:474-8.

4. Bhatnagar A, Mayberry J, Nirula R. Rib fracture fixation for flail chest: what is the benefit? J Am Coll Surg 2012;215:201-5.

5. Kerr-Valentic MA, Arthur M, Mullins RJ, Pearson TE, Mayberry JC. Rib fracture pain and disability: can we do better? J Trauma 2003;54:1058-63; discussion 1063-4.

6. National Institute for Health and Care Excellence. Insertion of metal rib reinforcements to stabilise a flail chest wall, 2010. Available at: https:// www.nice.org.uk/guidance/ipg361/resources/insertion-of-metal-ribreinforcements-to-stabilise-a-flail-chest-wall-pdf-1899867689121733. Accessed on 1 January 2020.

7. Dehghan N, de Mestral C, McKee MD, Schemitsch EH, Nathens A. Flail chest injuries: a review of outcomes and treatment practices from the National Trauma Data Bank. J Trauma Acute Care Surg 2014;76:462-8.
Jolie Hwee, ${ }^{1}$ MMed (Surg), MRCS, MBBS,

Matthew Yeo, ${ }^{1}$ FAMS (Plast), FEBOPRAS, MMed (Surg),

Michelle Ho, ${ }^{1}$ FAMS (Plast), MMed (Surg), MRCS,

Dokeu Aneez, ${ }^{2}$ FRCS (CTH), FRCS (GS), MBBS,

Chong Han Pek, ${ }^{1}$ FAMS (Plast), MMed (Surg), MRCS

${ }^{1}$ Division of Plastic, Reconstructive and Aesthetic Surgery, Department of General Surgery, Tan Tock Seng Hospital, Singapore

${ }^{2}$ Division of Thoracic Surgery, Department of General Surgery, Tan Tock

Address for Correspondence: Dr Jolie Hwee, Division of Plastic, Reconstructive and Aesthetic Surgery, Department of General Surgery, Tan Tock Seng Hospital, 11 Jalan Tan Tock Seng, Singapore 308433. Email: joliehwee@gmail.com
Seng Hospital, Singapore 